\title{
The German online media market: Online-born information offerings and their audiences - A shift towards digital inequalities? ${ }^{1}$
}

\section{Céline Fabienne Kampes ${ }^{2}$}

Department of Business Studies, University of Applied Sciences Düsseldorf, Germany Inga Brentel

Department for Communication and Media Studies, Institute of Social Science, Heinrich-Heine-University, Germany

To cite this article: Kampes, C. F., \& Brentel, I. (2020). The German online media market: Onlineborn information offerings and their audiences - A shift towards digital inequalities? World of Media. Journal of Russian Media and Journalism Studies 4: 5-34. DOI: 10.30547/worldofmedia.4.2020.1

\begin{abstract}
$^{3}$
Media market and media-related inequalities in society have been intensively discussed in academia. Yet it is unclear if the online media market environment reproduces existing inequalities, smoothens them or even creates new ones among media offerings and users, potentially reinforcing a social divide. In this study, we test to which extent inequalities found are truly digital-induced or reproduced from offline context using the German Longitudinal IntermediaPlus 2014-2016 dataset and descriptive statistics. Based on an integrative analysis we combine the perspectives of German media offerings (supply side) and media audiences (demand side). We rely on the comparison of the genre portfolios of offline-originated and online-born media offerings to evaluate inequalities in the German online media market, based on past research, assuming that offline-originated media providers primarily replicate their strategic product portfolio from the offline media market to the online media market. Using the media providers' origin, we identify a typology of offline-originated and onlineborn media offerings. For inequalities in media use and potentially resulting social divides we refer to research on the knowledge gap hypothesis and digital

${ }^{1}$ This research was supported by the Digital Society research program funded by the Ministry of Culture and Science of the German State of North Rhine-Westphalia.

${ }^{2}$ Corresponding author:

Céline Fabienne Kampes, Münsterstraße 156, 40476 Düsseldorf, Germany.

Email: celine.kampes@hs-duesseldorf.de

${ }^{3}$ This article is based on a presentation at the 11th International Media Readings in Moscow "Mass Media and Communications" in 2019. We thank all participants who gave us fruitful feedback and thus helped to advance our study to the article it is today.
\end{abstract}


divide studies. For 2016, we found German online-born media offerings having a thematically contradictory, entertainment-focused product portfolio that balances existing offline-originated inequalities. However, it provokes a 'silent' de-polarization, with political offerings almost exclusively offline-originated evolving into a niche market on the supply side. On the demand side, we found stronger inequalities in the use of offline-originated online media offerings by gender, education and socio-economic status. These mainly mirror the inequalities known from the offline context. For age, we found uniquely digital inequalities in online media use.

\section{Keywords}

Digital inequalities, German online media offerings and use, online-born offerings, knowledge gap, digital divide.

\section{Introduction}

In this study, we analyse if digitalization balances, reinforces, or creates new inequalities in the German online media market and whether it reinforces, or creates, new social divides. We combine the market perspective (supply side) with the audience perspective (demand side) and differentiate between onlineborn and offline-originated online media offerings to identify digital, onlineborn, and offline-originated inequalities.

First, for our analysis on supply- and demand-sided inequalities we review relevant literature from the offline context as well as the online media surrounding and refer to the online media market conditions and media-specific strategic orientation of media providers. Next, we formulate our hypotheses to test whether inequalities amongst online-born and offline-originated media offerings and their users' socio-demographic background in the German online media market are new or mirror inequalities from the offline context. To identify digital (what we define as 'online-born') and offline-originated inequalities, we use an innovative approach that rests on the market supply perspective when analysing digital inequalities in online media use. The explanatory power of our analysis is supported by our unique, very detailed dataset, the Longitudinal IntermediaPlus 2014-2016 as our basis to determine the characteristics of offline-originated and online-born offerings to assess supply- and demandsided inequalities in the German online media market using descriptive statistics.

Referring to the online media market conditions and media-specific strategic orientation of media providers, we operationalize supply-sided inequalities 
using the number and media reach of genre-specific online media offerings. They serve as structural and economic determinants of media providers' individual product portfolio, that, in its entirety, centrally characterizes media supply in (online) media markets. We proceed from the assumption that online media offerings from offline-originated media providers primarily correspond to their offline portfolio (Carpenter, 2010: 1069; Gentzkow \& Shapiro, 2008: 147; Sjøvaag \& Kvalheim, 2019: 299). Using the typology of offline-originated and online-born offerings, we identify genre portfolio gaps to delimit offlineoriginated and online-born inequalities on the supply side. Build on this, we compare the audiences of offline-originated and online-born online media offerings. We calculate media use gaps for audiences in the most common socio-demographic metrics that have been found to account for online media use variation (e.g. Ragnedda et al., 2020: 796f, 804f; Peiser \& Jandura, 2015; van Deursen \& van Dijk, 2013: 520; Zillien \& Hargittai, 2009; Wei \& Hindman, 2011: 224), namely: age, gender, education, income and socio-economic status (SES). We investigate whether online media use inequalities are newly created through digitalization or originating from the offline context, that they mirror offline media use and are replicated in digitalization.

Next, we briefly describe the German online media market dataset, combining supply-sided information per offering (i.a. media-type origin and thematic genre) and demand-sided information on users' social background. The operationalization of the supply- and demand-sided digital inequalities serves as the basis for our analysis and results. We compare these with findings on offline-originated inequalities to triangulate our new research design. Our conclusion section summarizes our main findings and its implications for German society.

\section{Inequalities in online and offline media markets}

Media-related social inequalities have always been discussed intensively while new media genres emerged in societies (Allen \& Miller, 2000: 47; Dutton \& Reisdorf, 2019: 3; van Dijk, 2005; van Dijk, 2020: 4; Zillien, 2006: 70). It is understood that the online media market environment may reproduce existing inequalities, or even create new ones (Zillien \& Marr, 2013: 55). Some fear the innovating online media market conditions may trigger genre-specific information supply inequalities to the disadvantage of the normatively desired (thematic) representation of online media offerings (Dahlgren, 2009: 37; Hallin \& Mancini, 2004: 277; Kiefer \& Steininger, 2014: 27; Klinenberg, 2005: 61; Sjøvaag \& Kvalheim, 2019: 294ff, 302). This would put the democratically 
desired, integrative, and central information functions of online media at risk, (Cunningham, 2018: 44; Mancini, 2013: 44; Ragnedda \& Mutsvario, 2018: 2ff; Sjøvaag \& Kvalheim, 2019: 294) whilst the unequal use of information offerings further increases the knowledge gap amongst media audiences rather than decreases it (Tichenor et al., 1970: 159f). When media cannot fulfil its information function, digital inequalities in media supply and use could result in a social divide and social exclusion. This would undermine the initial hope that the online media (environment) could redress existing knowledge gaps and underlying social inequalities (Dahlgren, 2009: 9, 41; Wei \& Hindman, 2011: 229), instead increasing the democratic divide through social exclusion (Norris, 2001: 230f; Ragnedda et al., 2020: 795).

Although often solely focused on the media market's demand side, the extant literature recommends including both the supply and demand side of the online media market when analysing digital inequalities (Bonfadelli, 2002: 71f; Owen \& Wei, 2019). Focusing on the supply side, it becomes apparent that the online media market, in particular, has undergone radical changes compared to offline media markets (Lee, 2007: 745; Pira International, 2003: 16; Robinson et al., 2015: 578). Two characteristics tend to favour digital inequalities amongst genre-specific online media offerings whilst indirectly equally impacting online media use. First, increased technological possibilities (Jensen \& Sund, 2017: 289, 291) allow innovative business models focussed on commerciallyoriented activities and offerings (e.g. e-commerce) (Hendrickx, 2020: 5; Marr, 2006: 268). Second, a democratization of market barriers for new online media providers (Allen \& Miller, 2000: 57; Napoli, 2019: 93; Pira International, 2003: 124; Cunningham, 2018: 38, 43) diminishes the once-existing journalistic gatekeeping function (Budzinski \& Kuchinke, 2020: 25; Cunningham, 2018: 37; Dahlgren, 2009: 37). Both characteristics create a digital environment that allows more-heterogeneous structures of media offerings compared to offline media markets on the supply side (Campbell \& Grimm, 2019: 111) and ultimately shifts the gatekeeping function with an increasing need of media selection to the users.

New, pure online-born media providers, especially take advantage of these characteristics with their offerings (Cunningham, 2018: 38, 43; Egan \& Tsao, 2015: 4; Kiefer \& Steininger, 2014: 24, 26f; Sjøvaag \& Kvalheim, 2019: 302). In contrast, media providers with offline-originated online media offerings primarily mirror their offline product portfolio (Carpenter, 2010: 1069; Gentzkow \& Shapiro, 2008: 147; Sjøvaag \& Kvalheim, 2019: 299). Differentiating between the genre portfolio of offline-originated and online- 
born offerings enables us to isolate new supply-sided digital, online-born from already existing offline-originated inequalities in the genre-specific supply of online media offerings. It also enables us to define a product portfolio typology of offline-originated and online-born offerings resulting in two thematic genres that serve as the empirical basis for analysing demandsided digital inequalities in online media use among socio-demographic metrics.

\section{Supply-sided inequalities: Thematic genre metrics}

The extent to which the genre portfolio of online-born and offline-originated online media offerings differ, forms the basis for our analysis of supply-sided digital inequalities. It refers to the structure of thematic genres offered within the product portfolio. In the offline media market, the product portfolio offered is characterized by the supply of genres whose information value is rather high from a normative, democratically relevant perspective, e.g. business, culture, economy, news, politics or regional (Brekken et al., 2012: 67f; Gentzkow \& Shapiro, 2008: 147; Sjøvaag \& Kvalheim, 2019: 304). The product portfolio and its respective media providers are characterized by their journalistic selfperception (Carpenter, 2010: 1069; Dahlberg, 2007: 838; Gentzkow \& Shapiro, 2008: 147; Sjøvaag \& Kvalheim, 2019: 299). From past research (Carpenter, 2010: 1069; Gentzkow \& Shapiro, 2008: 147; Sjøvaag \& Kvalheim, 2019: 299), we can assume that offline-originated media providers primarily replicate their genre-specific portfolio from the offline media market to the online media market. Thus, to distinguish new, digital inequalities from existing inequalities, the offline-originated product portfolio of offerings serves as our assessment scale.

In contrast, online-born offerings and their media providers follow commercial, rather than journalistic, maxims of action (Cunningham, 2018: 38, 43; Egan \& Tsao, 2015: 4; Hallin \& Mancini, 2004: 277; Kiefer \& Steininger, 2014: 24, 26f; Sjøvaag \& Kvalheim, 2019: 302). They aim to benefit from a maximized economic efficiency (Hendrickx, 2020: 2; Küng, 2001: 222; Whitney et al., 2004: 406). These emerging, numerically increasing online-born media offerings tend to focus on high media reach and audience-maximizing content strategies; especially strategies with particularly low production costs (Anderson \& Gabszewicz, 2006: 570; Gentzkow \& Shapiro, 2008: 147; Hamilton, 2011: 16; Küng, 2001: 223; Sjøvaag \& Kvalheim, 2019: 295f). Consequently, a commercially-dominated product portfolio contains entertainment-oriented thematic offerings that lack "the breadth and depth of stories" (Brekken et al., 
2012: 65) and include entertainment, family, health, lifestyle or sports genres (Brekken et al., 2012: 70). An increasing orientation towards content's commercial usability is posited to negatively impact the normatively desired (thematic) representation of online media offerings (Dahlgren, 2009: 37; Hallin \& Mancini, 2004: 277; Kiefer \& Steininger, 2014: 27; Klinenberg, 2005: 61; Sjøvaag \& Kvalheim, 2019: 294ff, 302).

Based on the online media market conditions and strategic orientation ascribed to online-born media offerings and their media providers in past research, we expect digital inequalities to appear from differences in the thematic genre portfolio comparing offline-originated and online-born information offerings (genre portfolio gaps). Based on the number and media reach as metrics of genre-specific online media offerings building the structural and economic determinants of online media market supply, our first hypothesis predicts:

H1: Patterns of inequalities in the genre portfolio identified by the number and media reach of online-born offerings will differ from those of offlineoriginated offerings.

If the genre portfolio of online-born offerings differs from the offlineoriginated genre portfolio, genre portfolio gaps exist. If existing, we aim to identify the characteristics of genre portfolio gaps, drawing on the existing literature that ascribes different normatively charged maxims of action to online-born and offline-originated media providers (i.a. Anderson \& Gabszewicz, 2006: 570; Dahlgren, 2009: 35; Gentzkow \& Shapiro, 2008: 147; Küng, 2001: 223; Sjøvaag \& Kvalheim, 2019: 293ff, 302), leading to $\mathrm{H} 2$ :

H2: Genre portfolio gaps among online-born and offline-originated offerings will be characterized by the former's skew toward entertainment-oriented genres based on the number and media reach of offerings.

If true, online-born offerings should supersede offline-originated offerings and their media provider from the online media market with economic-oriented maxims of action. This would enforce a de-politicization, to the detriment of genres perceived as having special importance for society's democratic constitution (Hindman, 2009: 100, 131; Cunningham, 2018: 44). If true, this may negatively influence online media audiences' media consumption (Mancini, 2013: 45f). To analyse digital demand side inequalities, the characteristics of online-born versus offline-originated offerings is reduced to two genres, as typical cases. 


\section{Demand-sided inequalities: Socio-demographic metrics}

Yet it is unclear to what extent online media is producing new inequalities or mirroring existing ones (van Deursen \& van Dijk, 2013: 521f; Wei \& Hindman, 2011: 217f). Offline media use inequalities in audience's socio-demographic metrics have been observed in well-educated men, with a high SES, use media such as newspapers, while those with lower education, and SES, use television as an information source (Bonfadelli, 2002: 69; Peiser \& Jandura, 2015; Wei \& Hindman 2011, 222). Television is dominated by commercial channels that are supposed to be entertainment-oriented and, therefore, lower on political-information supply (Bonfadelli, 2002: 71). As online-born media offerings are more commercially- and entertainment-oriented (Cunningham, 2018: 38; Brekken et al., 2012) a similar pattern of audiences' sociodemographic characteristics to that of television audiences could be assumed. For age, increases in offline media use throughout the lifecycle has been demonstrated and decreasing again approaching old age (Peiser \& Jandura, 2015).

Initially, online media access inequalities were attributable to technical and economic barriers (Bonfadelli, 2002: 72; van Deursen \& van Dijk, 2013: 521f), known as first digital divide. Later, social demographics accounted for much of the observed variation in online media use, the second digital divide. SES - although measured in different ways - proved to be a good predictor for online use (Zillien \& Hargittai, 2009: 278, 284ff). Men use online media (as information source) more frequently than women (Initiative D21, 2016: 13; Bonfadelli, 2002: 78ff; Wei \& Hindman, 2011: 226), welleducated people use them more than less-educated people (Initiative D21, 2016: 14; Bonfadelli, 2002: 77ff). Further, the well-educated and those with a higher SES are able to more efficiently search for information (Zillien \& Hargittai, 2009: 288). Older people are online less frequently than younger ones (Initiative D21, 2016: 13, 58) and younger people use online media news more often than older people (Peiser \& Jandura, 2015), despite the fact younger cohorts mostly use online media for entertainment (Bonfadelli, 2002: 80).

Consistent with these prior, mainly digital divide research findings, our third hypothesis predicts:

H3: Patterns of inequalities in the online media audience sociodemographic metrics of gender, education and SES will mirror those of offline media. 
The knowledge gap hypothesis and digital divide literature review showed different inequalities in offline and online media use for age (see e.g. Ragnedda et al., 2020: 808f; Peiser \& Jandura, 2015) our fourth hypothesis is:

$\mathrm{H} 4$ : Patterns of inequalities in the online media audience socio-demographic metric of age will differ from those of offline media.

If our demand-sided hypothesis withstands falsification, we can conclude online media use inequalities mainly mirrored the offline-context, and are not new. But for age, there would be newly created inequalities through digitalization; they would be real digital inequalities in media use requiring special attention for (new) actions to be taken countering social exclusion.

\section{Research Approach}

Our research approach isolates online- and offline-related effects. The online media market can create digital inequalities (Zillien \& Marr, 2013: 55), and in contrast to existing inequalities, these digital inequalities are caused by the digital environment and impact both supply- and demand-related structures within the online media market. Online media market analysis, of course, must also control for any offline contexts that might appear to attribute to the online media market inequalities that actually originate from the offline media context (van Dijk, 2020: 6). Accordingly, our supply-sided analysis of the online media market distinguishes between the media-type origin of the media providers resulting in online-born and offline-originated online media offerings. The empirical results on the demand side are based on two thematic genres each characteristically for online-born and offline-originated media offerings compared to inequalities known from offline media use. We thus cover two dimensions that Bonfadelli (2002: 71) defined for analysing potential media-related social inequalities: first, caused by inequalities in information supply, and second, by its use.

\section{Data}

We used the Longitudinal IntermediaPlus (2014-2016) to test our H1-H4, predicting the sources of digital inequalities in the German online media market using the most recent year: 2016. This unique and representative dataset for online media use in Germany is collected from Germany's leading mediaanalysis agencies and is limited to non-public, private online media offerings. It combines variables for cross-media use (press-media, radio, tv and online), socio-demographic metrics and a respondents' background for German speaking 
residents of Germany 14 years of age and older. The data is collected via survey and technical measures based on digital trace. This enables us to refer to the actual use of online media (covered by the variables page impressions and daily-basis use) and not on potentially biased self-declarations of respondents going beyond aggregated use categories as in past research of digital divide and knowledge gap hypothesis (e.g. van Deursen \& van Dijk, 2013; Zillien \& Hargittai, 2009; Bonfadelli, 2002). Further, our analysis benefits from the detailed online media supply and use data on the level of single website offerings (e.g. FAZ/politics) and its added supply-sided information (i.a. thematic genre per offering). For 2016 - the year used for our analysis - the dataset includes over 4,300 online media offerings and 300,000 people. This new Longitudinal IntermediaPlus (2014-2016) data is made accessible for academic use by Brentel et al. (2020; Brentel \& Winters, forthcoming) augmented with supply-sided primary data (see Kampes, 2020).

\section{Operationalization of metrics}

Offerings: The underlying strategic business model of media offerings (structured as connection, content, context, commerce (Wirtz, 2018: 307-309) and games) delimitates the extended business model options within the online media market (Marr, 2006: 268; Hendrickx, 2020: 5; van Dijk, 2004: 151) and dataset to information offerings. These are of special importance for the decision building process in society (Christians et al., 2009; Iversen \& Knudsen, 2019) and thus in focus when analysing digital inequalities. Further, they are enriched with primary data on the media-type origin of the respective media provider to distinct two samples: offline-originated and online-born information offerings. The media-type origin is derived from the media provider's initial media background either originating offline (newspapers, magazines, tv or radio channel) or online. However, for the distinction of online-born versus offline-originated offerings the latter exclusively refers to newspaper and magazine offerings. The delimitated dataset for the supply-sided analysis consists of 1,152 offlineoriginated and online-born information offerings resulting in two genre product portfolios.

Genres: The information offerings are structured by thematic genres that were identified inductively and assigned originally based on 24 different genres (Kampes, 2020: 32ff). However, for our study, the genres 'Nachrichten' (German word for news), 'news' and 'newsletter' were merged to news as neither the language of presented news, nor their form of presentation is of relevance. This results in a total of 22 genres: advice, car, career, culture, digital, 
economy, entertainment, family, finance, forum, games, health, knowledge, lifestyle, news, politics, real estate, regional, soccer, sports, style and travel. The analysis of thematic genres within the product portfolio is based on their number and media reach. The media reach consists of page impressions from a three-months-period ${ }^{4}$ provided in the Longitudinal IntermediaPlus (2014-2016). As the number of offerings and cumulated media reach varies amongst onlineborn and offline-originated offerings, the analysis bases on the relative number and media reach of information offerings.

Users: We have defined two categories of users: a 'user' is someone who has used the website entity at least one day in a three-month-period while a 'regular user' is someone who has used the website entity on an average of at least one day per week. This is done by aggregating the variable 'Nutzung tagesbasis', the daily-based use of an information offering for a respondent indicating the number of days in a three-month period a respondent used the information offering. ${ }^{5}$

Socio-demographic metrics: The audience is characterised based on the variables age, gender, education and income. Age is coded for twelve cohorts in four-year steps beginning with ' $14-19$ ' and ending with '70 or older'. Gender comprises two categories: men and women. Education is measured in four categories and aggregated to the three categories low, mid and high education, where the categories of 'matriculation standard' and 'university' are pooled. Education is further combined to an additive index with income ${ }^{6}$ to create a variable for SES having again three categories, low, mid and high SES.

${ }^{4}$ The page impressions from a three-months-period are constructed as an average of two three-month-periods (October to December 2015 and January to March of 2016) (Brentel et al., 2020).

${ }^{5}$ If a respondent has more than 0 contacts with one online-offering of the genre (variable 'Nutzung tagesbasis' of a genre greater than ' 0 ') it is a user of the genre; If a respondent has at least 13 contacts within the three-month period he or she uses the genre at an average of once a week and is seen as a regular user; if a respondent has more than 89 contacts with an online offering of the genre he or she is defined as a daily user of the genre. A three-months-period is constructed as an average of two three-month-periods (October to December 2015 and January to March of 2016) (Brentel et al., 2020).

${ }^{6}$ Income is measured in eight categories and aggregated to the three categories low (less than 1,500 Euros), mid (1,500 to 2,500 Euros) and high (2,500 Euros and more) income. For the SES index, smaller than 1.5 was coded as "low", 1.5 and smaller 2.5 as "mid", and 2.5 and above as "high" SES. 


\section{Methods of analysis}

Descriptive statistics were used to analyse the genre portfolios of online media offerings and socio-demographic characteristics of the audience grouped to allow the comparison of offline-originated and online-born offerings by respective genres. To reveal the existence of digital inequalities on the supply side (H1), we compare the thematic characteristics of the genre portfolio of offline-originated and online-born offerings on their entirety based on their numerical and media reach-related distribution. Following a brief description of both genre portfolios, we perform a linear correlation analysis for both genre metrics (number and media reach) for the offline-originated and onlineborn genre portfolio. With the genre portfolio of offline-originated offerings corresponding to the offline media market (Carpenter, 2010: 1069; Gentzkow \& Shapiro, 2008: 147; Sjøvaag \& Kvalheim, 2019: 299) and thus serving as the assessment scale for digital inequalities, a linear correlation to the online-born genre portfolio would state that genre portfolio gaps as new, digital inequalities do not exist, rejecting H1. It would result in a duplication of offline-originated inequalities through online-born offerings in the online media market. The absence of a correlation between the offline-originated to the online-born genre portfolio, thus demonstrating genre portfolio gaps confirming $\mathrm{H} 1$, further is the prerequisite for analysing $\mathrm{H} 2$.

To identify the characteristics of genre portfolio gaps (H2), we compare the numerical and media reach-related coverage of offline-originated offerings by online-born offerings per genre. The comparison of the offline-originated and online-born genre portfolio results in a three-step-characterization of gaps as forms of digital inequalities: First, thematic offerings that are underrepresented in both variables (numerical and media reach-related) within the online-born portfolio (illustrated below the assessment scale of 100 percent resembling the offline-originated distribution). In contrast, thematic genres above the assessment scale are overrepresented since online-born offerings supplement the online media market. Third, thematic offerings may be underrepresented with respect to one variable (either numerical or media reach-related) whereas overrepresented in terms of the other variable considered. According to literature, we expect online-born offerings to be overrepresented in terms of their number and media reach especially with respect to entertainment-oriented genres such as entertainment, family, health, lifestyle or sports (Brekken et al., 2012: 70). Genres whose information value is rather high from a normative, democratically relevant perspective like business, culture, economy, news, politics or regional are expected to rather be underrepresented within the online- 
born portfolio of offerings (Brekken et al., 2012: 67f; Gentzkow \& Shapiro, 2008: 147; Sjøvaag \& Kvalheim, 2019: 304) thus confirming H2. The description of both genre portfolios as well as the characteristics of genre portfolio gaps ultimately lead to a typology of both portfolios for which one genre each is identified as a typical case and analytical basis for the demand-sided analysis: the genres politics (offline-originated offerings) and digital (online-born offerings).

To test our third hypothesis, we calculate for each socio-demographic metric the gap between the groups of categories. For gender one group are men and the other are women, for education and SES we have three groups: low-, midand high-level education or SES. Men and the low-level groups of education and SES build the reference category. Doing so we follow the methodological approach of Bonfadelli (2002), who calculated these gaps for comparison in online media access and use to evaluate in his pioneer study to what extent the knowledge gap hypothesis is transferred to a digital divide. In our case, we compare the gaps among the audience of online-born media offerings with those of offline-originated online media offerings to evaluate the gaps, measuring unequal media use among those groups, as inequalities that are digital, thus online-born, or coming from the offline context, being offline-originated. We also consider the distribution of the different social groups in our data so we do not over or underestimate a gap found. We calculate the gaps for users, regular users and daily users to be able to compare the different groups among the frequency of their media use as e.g. men and well educated are expected to use online and offline media more (see Bonfadelli, 2002: 77, 79; Peiser \& Jandura, 2015).

Are the patterns of gaps, visualized by graph lines, following the same direction we can conclude that inequalities in online media use among those social metrics follow those known from offline media use. Are the graph lines differing in direction we have to reject $\mathrm{H} 3$ as the patterns of gaps for onlineborn and offline-originated online media offerings differ from each other. A steeper line for offline-originated offerings indicates a balancing effect of digitalization on media use. While a steeper line for online-born offerings signals a rather negative impact of digitalization on media use that might reinforce social inequalities. Additionally, we compare the patterns of gaps we find with the patterns of offline media use reviewed in the literature on knowledge gap hypothesis and divide research. Are these patterns of gaps, measured by the direction of the gaps, corresponding we can confirm our H3. 
We follow the same method to test our fourth hypothesis and use the age cohort of 14-19 years as reference category to calculate the gaps. As we expect truly digital inequalities in online media use among age, we have to reject $\mathrm{H} 4$, once the graph lines follow the same direction.

\section{Results}

The population of 1,152 German online information offerings served as the empirical basis to test the first and second, supply-sided hypotheses whereas the demand-sided third and fourth hypotheses are based on the genre politics, constituting of 16 offerings and 106 digital offerings identified as typical cases for offline-originated and online-born offerings.

\section{Genre portfolio of online-born and offline-originated offerings}

Offline-originated offerings include 572 information offerings (49.65\%) covering 34.43 percent of the cumulated media reach. This two-folded bias to the advantage of online-born offerings within the population reveals not only that the latter has a higher empirical probability to dominate thematic genres online. It further discloses genre-superordinate that offline-originated offerings tend to have a lower media reach and numerical representation in the overall online media market portfolio, whereas especially online-born information offerings are rather high-reach offerings with higher market impacts and (advertising-) revenue streams. Based on this brief introduction of the online media market offerings, we describe the offline-originated and online-born-specific genre portfolios as a basis to test the existence of genre portfolio gaps (H1) and if applicable, describe their characteristics (H2).

\section{Hypothesis 1: Existence of genre portfolio gaps}

Serving as assessment scale (Carpenter, 2010: 1069; Gentzkow \& Shapiro, 2008: 147; Sjøvaag \& Kvalheim, 2019: 299), the product portfolio of offlineoriginated information offerings is thematically balanced with none of the 22 genres representing more than ten percent of the numerical share of offline-originated information offerings (see figure 1 with genres in alphabetical order). The genres lifestyle $(8.22 \%)$, regional $(8.74 \%)$ and advice $(8.92 \%)$ dominate the relative number of information offerings in ascending order for 2016. Considering the media reach and thus market impact of offline-originated information offerings, the portfolio is characterized by the genres advice (10.32\%), digital (10.38\%), politics $(10.77 \%)$ and news $(13.52 \%)$ with the latter covering the highest relative share of media reach amongst offline-originated information offerings. 
Figure 1

Genre portfolio of offline-originated information offerings

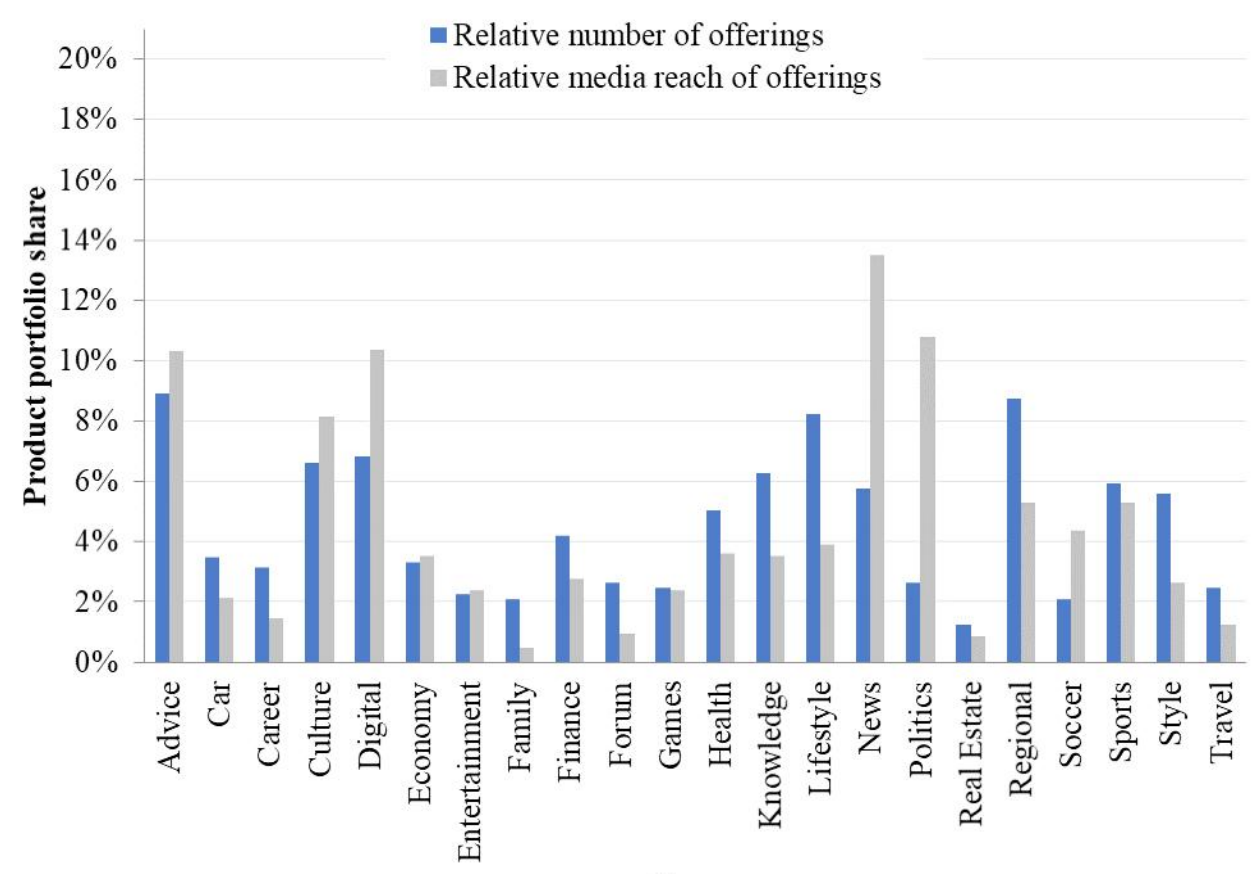

Genre

Source: Own figure

In contrast, the genre portfolio of online-born information offerings is more concentrated both in terms of the number and media reach of thematic genres (see figure 2). Online-born information offerings cover leadingly the genres finance $(10.86 \%)$, family $(11.21 \%)$ and digital $(11.55 \%)$ in terms of their relative numerical representation within the sample. The genre digital additionally belongs to the three leading thematic genres with respect to the relative media reach: It is the third most important genre with a relative media reach of 19.04 percent behind real estate $(19.69 \%)$ and style $(20.51 \%)$. 


\section{Genre portfolio of online-born information offerings}

Figure 2

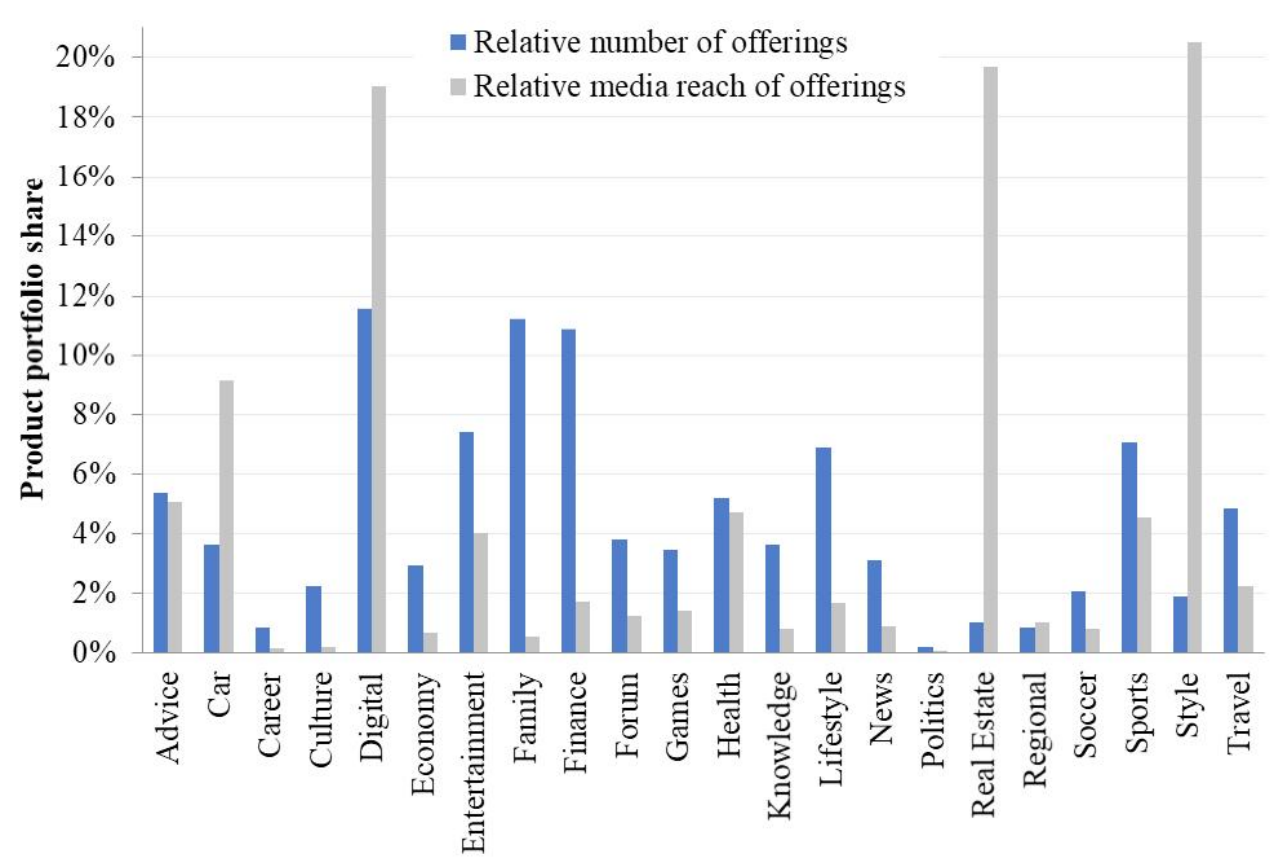

Genre

Source: Own figure

The short description of the two genre portfolios suggests that the genre portfolios do not correlate in their entirety, which is supported by the correlation analysis of both genre portfolios: As the p-value is larger than the significance level of .05 , no significant indication for a correlation between both genre portfolios exist neither for the number $(r=.106 ; \mathrm{p}=.637)$ nor for the media reach of offerings $(r=-.032 ; \mathrm{p}=.887)$. The genre portfolio of offline-originated and online-born offerings do not correlate in their entirety in terms of the number or media reach of genres. Based on the executed analysis, inequalities from the offline media are not duplicated in the online media market. Thus, new genre portfolio gaps as digital inequalities have arisen (confirming H1), whose characteristics are further characterized on a genre-specific level (H2). 


\section{Hypothesis 2: Digital inequalities - new genre portfolio gaps}

The comparison of the online-born and offline-originated genre portfolio (see figure 3) results in a three-step-characterization of genre portfolio gaps.

Figure 3

\section{Genre gaps between online-born and offline-originated offerings}

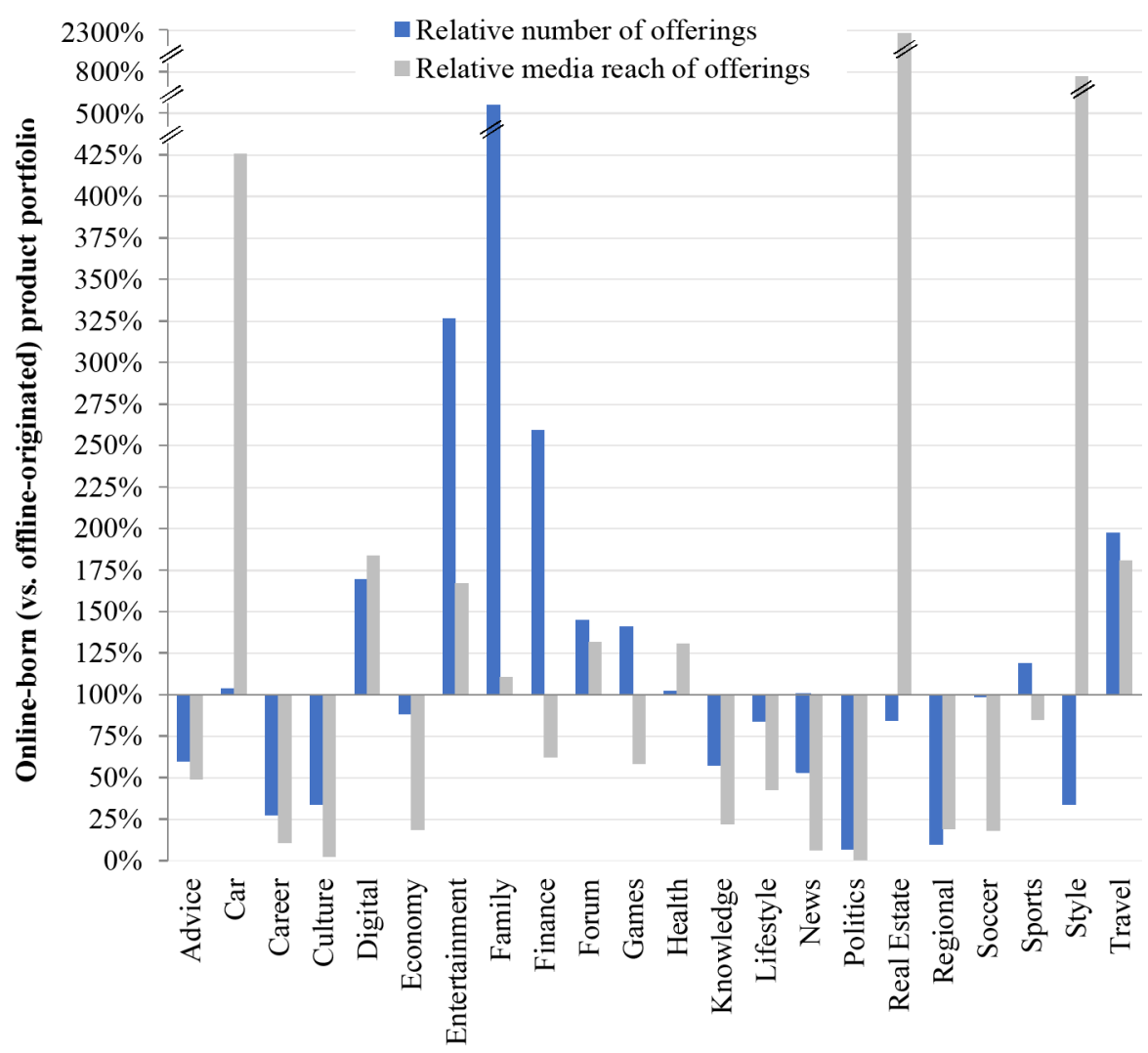

Genre

Source: Own figure

Underrepresented genres: In total ten genres are underrepresented within the online-born genre portfolio in terms of the number of offerings provided as well as their cumulated media reach compared to the offline-originated portfolio: advice, career, culture, economy, knowledge, lifestyle, news, politics, regional, soccer. Least numerically represented are career (27.39\%), regional $(9.86 \%)$ and politics $(6.57 \%)$. Concerning the relative media reach covered 
amongst the online-born offerings, news ( $6.41 \%)$, culture $(2.48 \%)$ and politics $(0.55 \%)$ are least represented in ascending order. In fact, only one single onlineborn political offering exists in 2016 so that politics is most underrepresented in terms of the number and media reach within online-born offerings. With culture, economy, news, politics and regional five genres complying a high democratic relevant information function (Brekken et al., 2012: 67f; Gentzkow \& Shapiro, 2008: 147; Sjøvaag \& Kvalheim, 2019: 304) are underrepresented and thus still dominated by offline-originated offerings in the German online media market.

Overrepresented genres: With car, digital, entertainment, family, forum, health and travel, seven genres are numerically and in terms of their media reach stronger represented amongst online-born information offerings. Whereas the genre family offers five times more offerings (534.20 \%) with entertainment $(326.21 \%)$ to follow, it only covers 110.45 percent of the media reach already covered by offlineoriginated offerings. In turn, the genre car covers with a slightly higher number of offerings (103.55 \%) a more than quadrupled media reach (425.71\%). In contrast, the digital genre is one of the genres equally overrepresented with respect to both variables covering with almost the double amount of offerings (169.43\%) an almost doubled media reach (183.51\%). With the overrepresented genres primarily fulfilling an entertainment-oriented information function (Brekken et al., 2012: 70), this characteristic can be ascribed to online-born information offerings in general. This is in line with past research expecting online-born media provider to offer rather commercially-motivated, entertainment-oriented genres (Dahlgren, 2009: 35; Sjøvaag \& Kvalheim, 2019: 293ff) supporting our second hypothesis (H2).

Under- and overrepresented genres: Five genres are simultaneously underand overrepresented within online-born offerings. With respect to the number of offerings provided, the genres finance (258.88\%), games (140.89\%) and sports $(118.92 \%)$ are overrepresented, but do not cover the media reach of offline-originated offerings. In contrast, the genre style is characterized by only a third of online-born information offerings that however have a high reach per offering (cumulated $776.55 \%$ of offline-originated offerings). The tendency for high-reach online-born offerings becomes even more apparent for the genre real estate that has with less offerings ( $84.53 \%$ ) a more than 22-times higher media reach $(2266.40 \%)$ than the offline-originated portfolio.

Due to the contradictory product portfolio of offline-originated and onlineborn information offerings, not only the overall diversity of genres increases but also the genre portfolio gaps identified above balance offline-originated inequalities in the online media market. Whereas the genres culture, news and politics have a media reach-related high share amongst offline-originated 
offerings, they are underrepresented within online-born information offerings balancing the former inequalities (Hindman 2009: 19). In turn, this equally applies to those media reach-related overrepresented genres car, real estate and style amongst online-born offerings that in contrast are underrepresented within offline-originated media offerings. However, especially within the context of the genre politics, the low number of offerings provided by offline-originated offerings $(2.62 \%)$ is even reinforced by its underrepresentation amongst online-born information offerings (6.57\%). In consequence, the proportion of political and further democratically relevant information offerings (e.g. news) decreased with online-born, entertainment-oriented offerings increasing in number and media reach. This 'silent' de-polarization evolves these socially relevant offerings to a niche market (Hindman, 2009: 100, 131).

Our findings are in line with past research ascribing the characteristics of high media reach, commercially-oriented offerings to online-born media offerings and their respective providers (Dahlgren, 2009: 35; Sjøvaag \& Kvalheim, 2019: 293ff) (H2). The genre-based description of offline-originated and onlineborn information offerings reveals new, digital inequalities arisen from genre portfolio gaps: The portfolio of offline-originated offerings is characterized by fewer offerings with lower media reach providing offerings but a high relevance for the democratic discourse in society, which especially applies to politics that they almost exclusively provide. In contrast, online-born offerings cover a high number of high-reach, entertainment-oriented information offerings. The genre digital characteristically represents online-born offerings. It has a leading market position in 2016 and is dominated in terms of number and media reach by online-born offerings. Therefore, the genres politics and digital serve as leading examples for offline-originated and online-born information offerings and are the basis for analysing demand-sided inequalities.

\section{Audience of typical online-born and offline-originated offerings}

Almost half of users ( $46 \%$ ) covered in our data are using online media offerings of digital genre while only a third (28\%) uses those of the politics genre. Since the digital genre includes the largest number of informationofferings online, this is not surprising. For political offerings the number of users is comparatively high as it is one of the genres with the fewest offerings and has only about one tenth of the offerings to catch users (see figure 1 and 2). Explanation offers the frequency of use: 2.7 percent of online users regularly use the offerings of politics genre compared to 1.9 percent for digital genre. That is 9.6 percent of politics-genre users and 4.2 percent of digital-genre users. 


\section{Hypothesis 3: Reinforced inequalities online}

Regards the distribution by gender in our data ( $+4 \%$ women), we see a strong gender gap in the direction of men, increasing with regular use (see figure 4). This pattern is similar to the one we know from offline media (Bonfadelli, 2002: 78ff; Wei \& Hindman, 2011: 226), but comparing the offlineoriginated offerings of politics genre with the mainly online-born offerings of digital-genre the slope for politics genre is steeper. This indicates a stronger gender-gap for the offline-originated offerings of the politics genre. Only the gender gap for daily users of digital-genre offerings is higher than regular users of politics genre and shows a huge increase of the gender gap ${ }^{7}$.

Figure 4

\section{Gender gap in online media use}

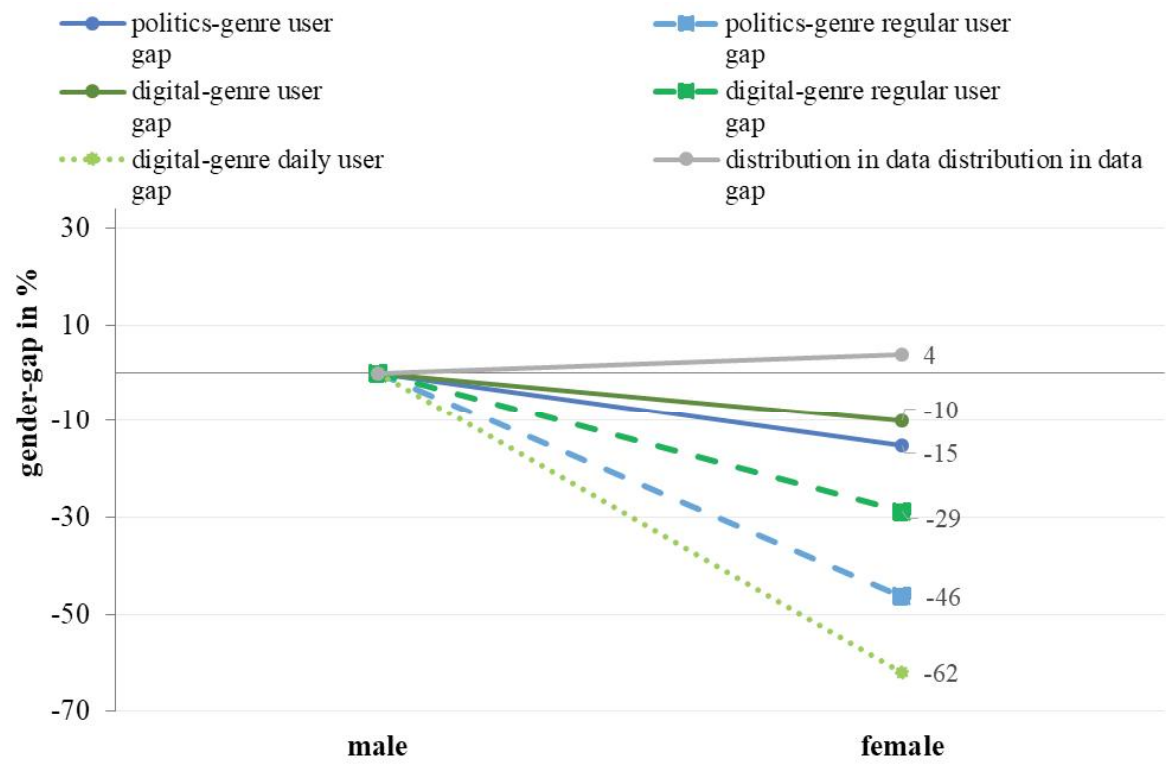

Source: Own figure

Notes: The distribution for gender in our data is $48 \%$ men and $52 \%$ female, among politics user it is $58 \%$ men and $42 \%$ female and for digital user it is $55 \%$ men and $45 \%$ female.

${ }^{7}$ For digital genre the number of users is 154,438 for regular users is 6,435 and daily users is 42 . For politics genre the number of users is 93,972 of regular users is 9,006 and of daily users: 6 . Due to the small number of daily users, those are not considered for the statistics. 
Looking at the educational level of the audiences we also see a similar pattern than in offline media use. However, here the media use of digital genre shows a higher gap for those with a low and mid-level education (see figure 5). If considering the distribution in our data this reverses: We see a lower underrepresentation of users with a lower education and almost an exact representation of those with a mid-level education (see notes of figure 5). The education gap for the politics genre is big for the highest education level and gets bigger with regular use. The overrepresentation is again lowest for the mid-level educated and - like the gap - biggest for high educated users. The education gap seems to be much stronger than the gender-gap especially considering low versus high educated people and their distribution in our data, even if the gap does not increase at the same rate as the gender gap when used regularly. This is in line with the findings of Wei and Hindman (2011: 226) as well as earlier studies of Bonfadelli (2002: 81) underlining the importance of education for predicting online media use particularly with regard to the differences between the offlineoriginated politics offerings and online-born dominated digital genre.

Figure 5

\section{Education gap in online media use}

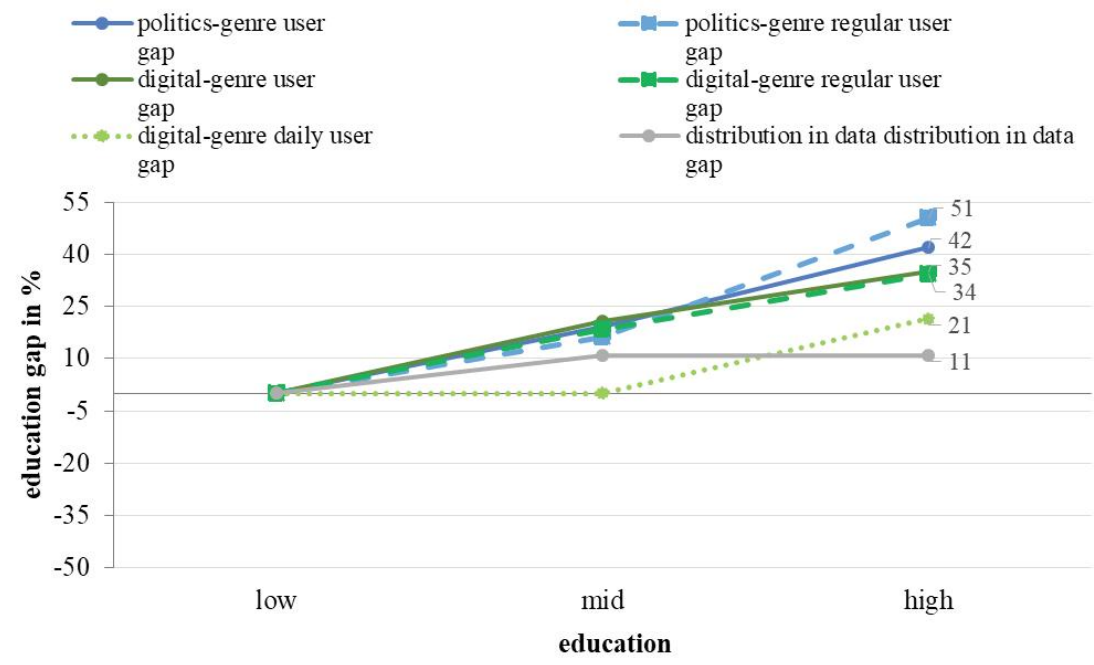

Source: Own figure

Notes: The distribution for education in our data shows $26 \%$ with a low, $37 \%$ mid and $37 \%$ high level education, among politics user it is $13 \%$ low, $32 \%$ mid and $55 \%$ high levelled educated and for digital user are $15 \%$ low, $35 \%$ mid and $50 \%$ high-levelled educated. 
Characterizing the audience among the SES also mirrors the patterns of inequalities from old-media use (e.g. Wei \& Hindman, 2011; Peiser \& Jandura, 2015 ) and at the same time it is lower than our results for the education gaps (see figure 5). This is remarkable as the income usually positively correlates with online media use (and newspaper use) and SES gaps are anticipated to be wider than education gaps. It underlines again the relevance of education for inequalities in online media use. For digital-genre users we see a lower gap and more balanced distribution by the SES. A higher status is correlated with an increase of media use, especially, for regular users, considering the bias distribution in our data towards the mid-level SES (see figure 6). For politics-genre use we see the same patterns at a higher level, ignoring regular users with mid-level SES. Only regular use of politics offerings shows a substantial increase in the gap for high SES. Digitization seems to balance the inequalities in media use looking at SES as the offline-originated gaps, represented by politics-genre users, are on a higher level than digital-genre gaps, besides regular users with a mid-level SES.

Figure 6

\section{Socio-economic status gap in online media use}

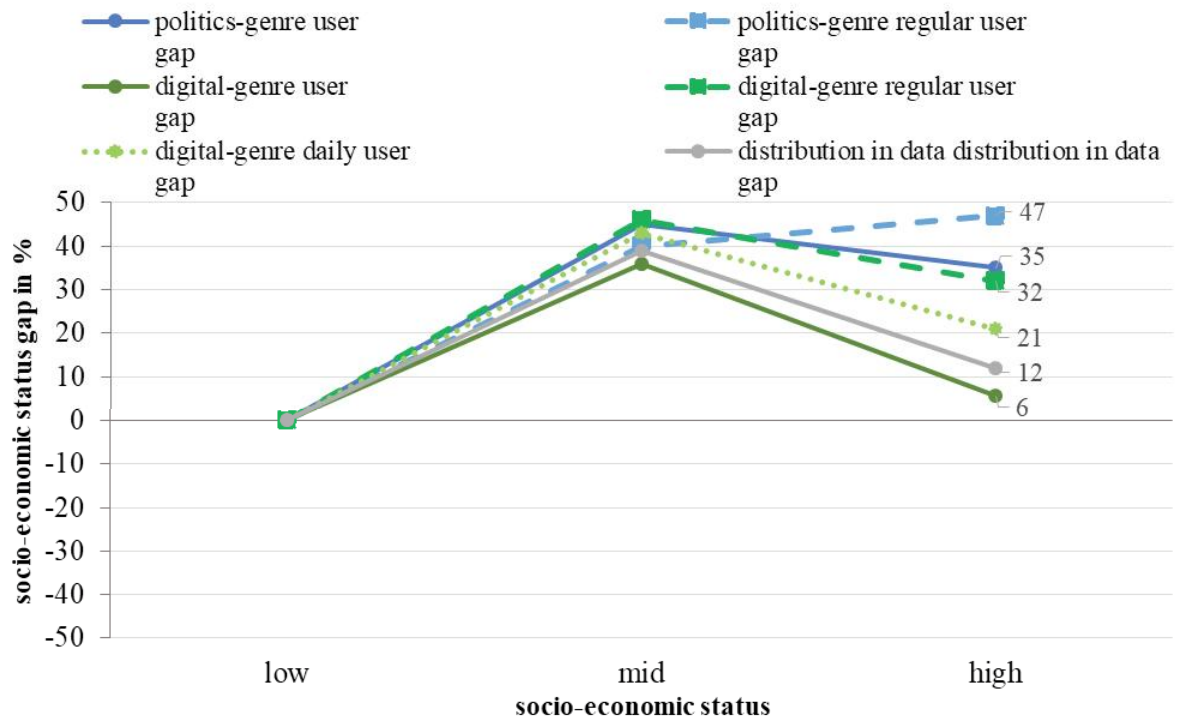

Source: Own figure

Notes: The distribution for SES in our data shows $16 \%$ with a low, $56 \%$ mid and $28 \%$ high SES level, among politics user it is $7 \%$ with a low, $52 \%$ mid and $42 \%$ high SES level and for digital user $8 \%$ low, $56 \%$ mid and $36 \%$ high SES level. 
These results show similar patterns of gaps among gender, education and SES of online-born and offline-originated online media offerings. Our findings also correspond with the patterns of offline media use found in the literature review. Therefore, we accept our $\mathrm{H} 3$ for gender, education and SES. As the graph for education shows a steeper slope of politics genre in the end, we can further conclude that there seems to be a reinforcing effect on online media use for high-level educated groups.

\section{Hypothesis 4: Digital inequalities - a new age gap}

In case of age it is noticeable that the lines for the gaps in politics-genre of figure 7 are constantly at a much higher level than digital offerings - leaving aside the outlier for daily use of digital genre at the age of 50 to 59. Also considering the distribution in our data the use of politics-genre offerings online is surprisingly high and overrepresented up to the age of 50, clearly differing from patterns known in old-media use.

\section{Age gap in online media use}

Figure 7

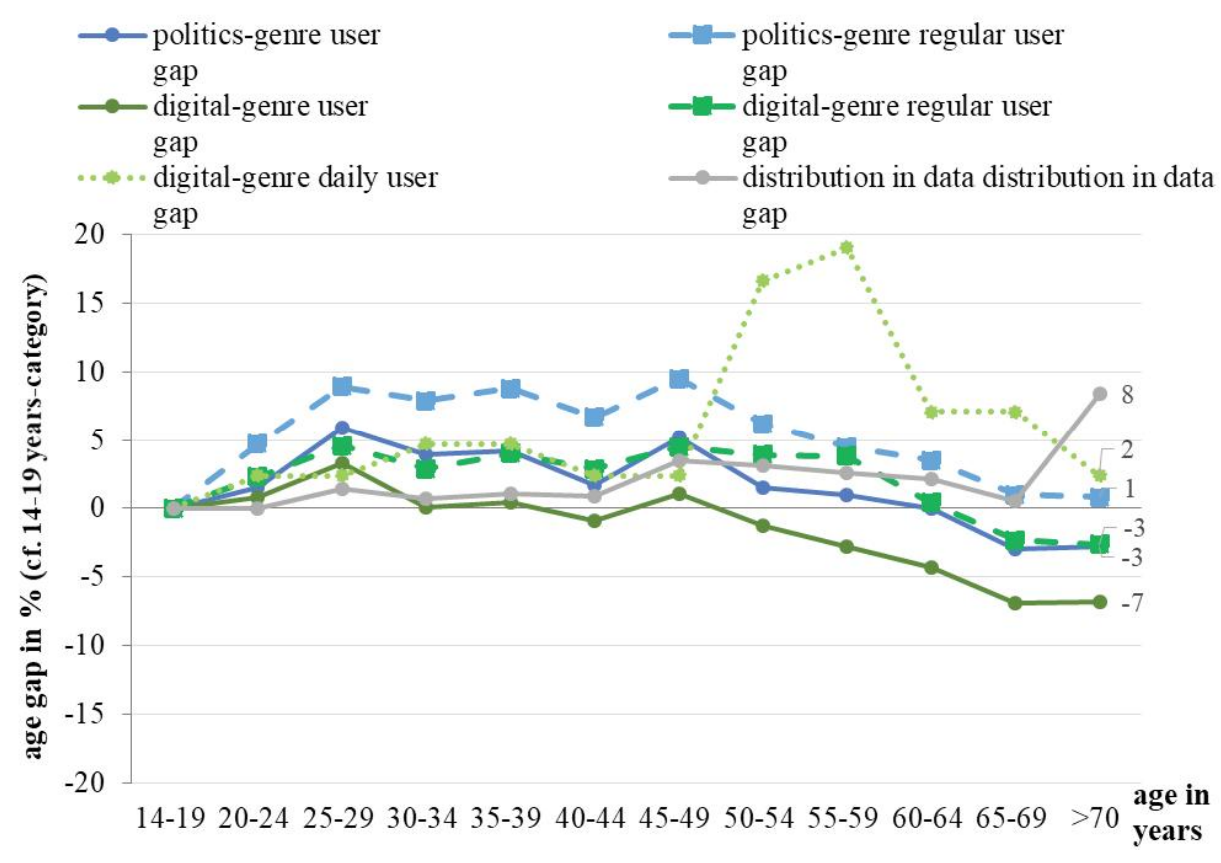

Source: Own figure 
However, the use of digital genre is higher for the cohorts younger 30 and following the observations made for (online and offline) news-media use (see figure 8). Still it is remarkable, that already at the age of 30 the use of politicsofferings is higher than of digital genre. For regular users the turning point is already at 25 years (politics-genre use $=12 \%$ vs. digital-genre use $=10.9 \%$ ) and there is another turning point at $50+$ years towards the use of digital genre (politics-genre use $=9.6 \%$ vs. digital-genre use $=10.2 \%$ increasing with rising cohorts). In sum, the results show a clear age gap differing from pattern of offline media use and confirming our assumption of a new digital inequality for age. We therefore accept our H4.

\section{Online media use differentiated for age}

Figure 8

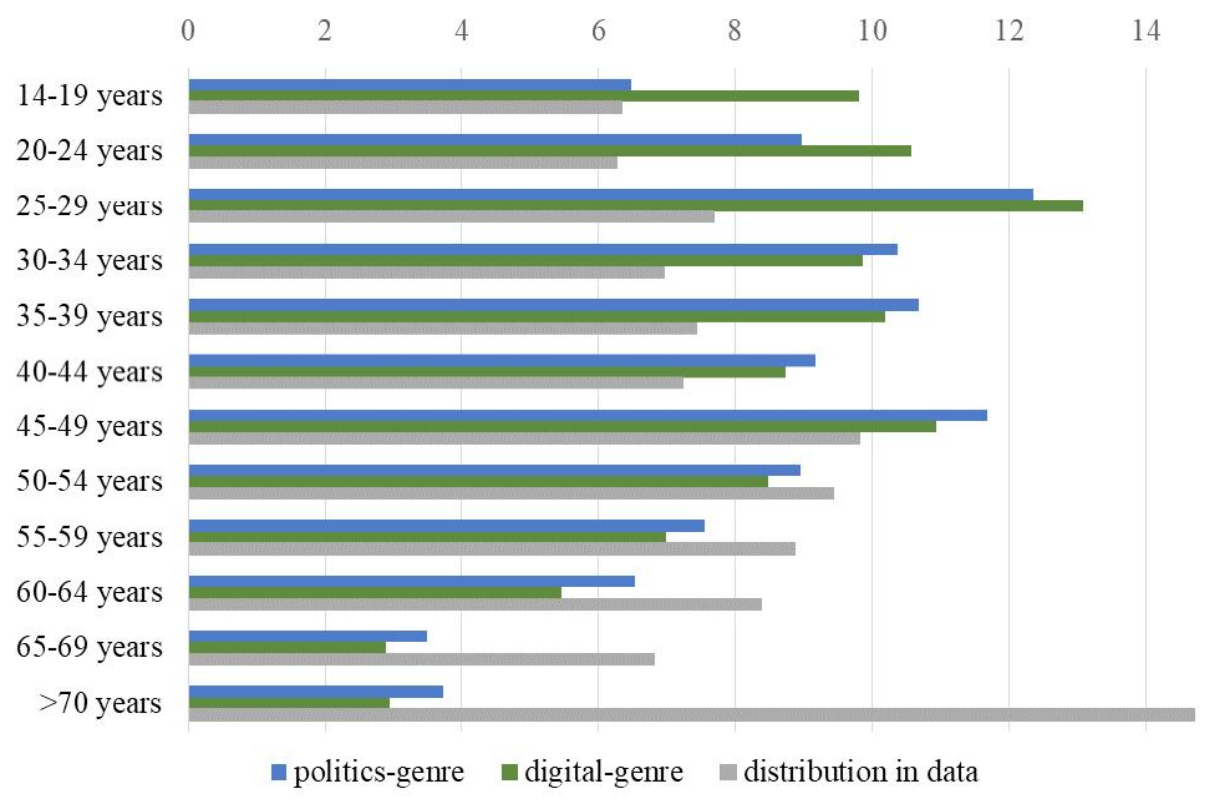

Source: Own figure

Our results also provide evidence for the third assumption (H3), that the patterns of inequalities in the audiences are similar to those known from offline media and are not explicitly digital inequalities, even though they seem partly stronger. When comparing offline-originated offerings of politics genre and the online-born dominated digital genre that effect becomes more apparent. 


\section{Conclusion}

Our analysis covers both the supply and demand side of the online media market and thus two of the five dimensions Bonfadelli (2002: 71) defined for analysing media-related social inequalities: inequalities in information supply and the use of them. Inequalities in information supply were revealed based on the comparison of offline-originated and online-born information offerings. We found that the offline-originated product portfolio is not replicated genresuperordinate by the online-born offerings within the online media market. Instead online-born information offerings focus on high-reach media offerings primarily far from journalistic-established content as their product portfolio is numerically and media reach-related characterized by entertainmentoriented genres like car, digital, family, entertainment, style or real estate. In contrast, the analysis confirmed that offline-originated offerings stick to their value proposition from the offline world (Dahlberg, 2007: 838) focusing on normatively desired information offerings (e.g. news, politics, regional). The thematically contradictory product portfolio of offline-originated and onlineborn media offerings enlarges the overall diversity of genres offered, with online-born information offerings in part balancing existing offline-originated genre inequalities (Hindman, 2009: 19). The feared shift in guiding principles of online-born information offerings with their rather commercially-oriented maxims of action scarcely effect information offerings of special social impact (Hindman, 2009: 100, 131) as offline-originated information offerings still dominate genres such as politics and news. However, especially within the genre politics, the low number of offerings provided by offline-originated offerings compared to the overall offline-originated genre portfolio is even enforced by its underrepresentation amongst the genre-portfolio of online-born information offerings. Even though this might lead to the statement of a non-existing depolarization, the proportion of political and further democratically relevant information offerings (e.g. news) decreased with non-journalistic offerings increasing in number and media reach. This 'silent' de-polarization evolves these socially relevant offerings to a niche market (Hindman, 2009: 100, 131) underlining the persistence of the digital divide in the online media market (Hindman, 2009: 142).

The online media market has served to balance some existing inequalities on the supply side, but it has also created new ones (Fenton, 2010: 9; Hamilton, 2011: 15f; Hindman 2009: 19), which is equally applicable for the demand side of digital inequalities (gaps in the use of information media). The online media access is close to the ceiling-effect (Raggnedda \& Mutsvairo, 2018) with almost 
80 percent being online in 2016 and a rising trend (D21-Index, 2016: 54; Hölig \& Hasebrink, 2019). However, the access to information through online media use differs according to the gaps in online media use. Based on our findings, specifically digital in the inequalities in online media use is the pattern of age gaps and the relevance of education in predicting the audiences. As onlineborn offerings are usually more entertainment-oriented than offline-originated offerings our results also imply an answer to Bonfadelli's question if there is "a dominance of entertainment functions" (2002: 81) in online media use that could reason the relevance of education. Moreover, it can be assumed that the differences in the gap levels between the audiences of the two types of genres are linked to the degree of commercialisation resulting in a product portfolio increasingly used by online-based offerings, while offline-originated offerings tend to transfer the offline formats into their online offerings. This is similar to the effect known from newspaper and tv use (Wei \& Hindman, 2011: 222; Bonfadelli, 2002: 69)

As our findings for digital inequalities are geographically focused on Germany and for the analysis of information use limited to two typical genres for offline-originated and online-born information offerings, more exploration is needed geographically (including further media markets), thematically for the media use (including more genres) and time-related (including recent market data) to analyse digital inequalities in information supply and use. Further the dimension of gaps in the resulting knowledge (Bonfadelli, 2002: 71) could help to evaluate the consequences of those digital inequalities identified for possibly resulting social exclusion and social as well as democratic divides.

\section{References}

ALLEN, R. \& MILLER, N. (2000). Panaceas and promises of democratic participation: reactions to new channels, from the wireless to the World Wide Web. In: Wyatt, S. et al. (eds.). Technology and in/equality: Questioning the information society. London: Routledge.

ANDERSON, S., \& GABSZEWICZ, J. (2006). The Media and Advertising: A Tale of two-sided markets. In: Ginsburgh, V. A. \& Throsby, D. (eds.). Handbook of the Economics of Art and Culture. Volume 1. Amsterdam: Elsevier Science.

BREKKEN, T., THORBJØRNSRUD, K, \& AALBERG, T. (2012). News Substance: The Relative Importance of Soft and De-Contextualized News. In: T. Aalberg, \& J. Curran (eds.). How Media Inform Democracy. Taylor \& Francis.

BRENTEL, I., KAMPES, C. F., \& JANDURA, O. (2020). Media Analysis Data: Sample of The Longitudinal IntermediaPlus from 2014 to 2016 (Longitudinal 
MA-IntermediaPlus Sample). GESIS SowiDataNet, Cologne. Data file version 1.0.0. https://dx.doi.org/10.7802/2030

BRENTEL, I., \& WINTERS, K., (forthcoming). The Longitudinal IntermediaPlus (2014-2016): A Case Study in Structuring Unstructured Big Data. Research Data Journal for the Humanities and Social Sciences.

BONFADELLI, H. (2002). The Internet and Knowledge Gaps. European Journal of Communication, 17(1), 65-84. https://doi.org/10.1177/0267323102017001607

CAMPBELL, C., \& GRIMM, P. (2019). The Challenges Native Advertising Poses: Exploring Potential Federal Trade Commission Responses and Identifying Research Needs. Journal of Public, Policy \& Marketing. 38 (1). p. 110-123.

CARPENTER, S. (2010). A study of content diversity in online citizen journalism and online newspaper articles. New Media \& Society. 12 (7). p. 1064-1084. https:// doi.org/10.1177/1461444809348772

CHRISTIANS, C. G., GLASSER, T., MCQUAIL, D., NORDENSTRENG, K., \& WHITE, R. A. (2009). Normative Theories of the Media. Journalism in Democratic Societies. Amsterdam University Press.

CUNNINGHAM, B. M. (2018). Evolving Research and Theories in Media Economics. In: Albarran, A. B., Mierzejewska, B. I., \& Jung, J. (eds.). Handbook of Media Management and Economics (2nd ed.). New York: Routledge.

DAHLBERG, L. (2007). Rethinking the fragmentation of the cyberpublic: from consensus to contestation. New Media \& Society. 9 (5). p. 827-847. https://doi. org $/ 10.1177 / 1461444807081228$

DAHLGREN, P. (2009). Media and political engagement : citizens, communication, and democracy. Cambridge: Cambridge University Press.

DUTTON, W. H., \& REISDORF, B. C. (2019). Cultural divides and digital inequalities: attitudes shaping Internet and social media divides. Information, Communication \& Society. 22 (1). p. 18-38. http://dx.doi.org/10.1080/136911 8X.2017.1353640.

EGAN, B., \& TSAO, J. (2015). The Rise of native Advertising: an exploration of its impact on Advertising. Journalism and the Consumer. In: American Academy of Advertising (ed.), American Academy of Advertising Conference Proceedings. Chicago. p. 4-7.

FENTON, N. (2010). Drowning or Waving? New Media, Journalism and Democracy. In: Fenton, N. (ed.). New Media, Old News. Journalism \& Democracy in the Digital Age. Thousand Oaks, London, New Dehli: SAGE Publications.

FUCHS, C. (2008). Internet and society: Social theory in the information age. London: Routledge. 
GENTZKOW, M., \& SHAPIRO, J. M. (2008). Competition and Truth in the Market for News. Journal of Economic Perspectives. 22 (2). p. 133-154. https://doi. org $/ 10.1257 /$ jep.22.2.133

GIBBONS, T. (2015). Active Pluralism: Dialogue and Engagement as Basic Media Policy Principles. International Journal of Communication. 9 (1). p. 1382-1399.

HALLIN, D. C., \& MANCINI, P. (2004). Comparing Media Systems: Three Models of Media and Politics (Communication, Society and Politics). Cambridge: Cambridge University Press.

HAMILTON, J.T. (2011). All the News That's Fit to Sell. Princeton, London: Princeton University Press.

HARGITTAI, E., \& HSIEH, Y. P. (2013). Digital inequality. In: Dutton, W. H. (ed.). The Oxford Handbook of Internet Studies. Oxford: Oxford University Press.

HENDRICKX, J. (2020). Trying to Survive While Eroding News Diversity: Legacy News Media's Catch-22. Journalism Studies. 21 (5). p. 598-614. https://doi.org/10. 1080/1461670X.2019.1694430

HENWOOD, F., \& WYATT, S. (2019). Technology and In/equality: Questioning the Information Society. (Almost) 20 years Later. Digital Culture and Society. 5 (1). p. 183-194. https://doi.org/10.14361/dcs-2019-0111

HENWOOD, F. ET AL. (2000). Critical perspectives on technologies, in/ equalities and the information society. In: Wyatt, S. et al. (eds.). Technology and in/ equality: Questioning the information society. London: Routledge.

HINDMAN, M. (2009). The Myth of Digital Democracy. Princeton: Princeton University Press.

HO, C., \& TSENG, S. (2006). From digital divide to digital inequality: the global perspective. International Journal of Internet and Enterprise Management. 4 (3). p. 215-227. https://doi.org/10.1504/IJIEM.2006.010915

HÖLIG, S., \& HASEBRINK, U. (2019). Reuters Institute Digital News Report 2019: Ergebnisse für Deutschland. [Reuters Institute Digital News Report 2019: Results for Germany] Arbeitspapiere des Hans-Bredow-Instituts, 47, Hamburg: Verlag HansBredow-Institut.

INITIATIVE D21 (2016). Initiative D21: Jährliches Lagebild zur Digitalen Gesellschaft [yearly monitor of the digital society]. Retrieved from http:// initiatived21.de/app/uploads/2017/01/studie-Initiative D21-2016.pdf

IVERSEN, M. H., \& KNUDSEN, E. (2019). When politicians go native: The consequences of political native advertising for citizens' trust in news. Journalism. 20 (7). p. 961-978. https://doi.org/10.1177/1464884916688289

JENSEN, H., \& SUND, K. J. (2017). The journey of business model innovation in media agencies: towards a three-stage process model. Journal of Media Business Studies. 14 (4). p. 282-298. https://doi.org/10.1080/16522354.2018.1445158 
KAMPES, C. F. (2020). Welche Genres existieren für Online-Medienangebote? Eine Analyse der Themenstruktur aus Anbietersicht [What genres exist for online media offerings? An analysis of the thematic structure from the perspective of media providers]. In: Deiters, W., Geisler, S., Hörner, F. \& Knaup, A. K. (eds.). Die Kommunikation und ihre Technologien. Interdisziplinäre Perspektiven auf Digitalisierung. transcript.

KIEFER, M. L., \& STEININGER, C. (2014). Medienökonomik [Media economics] (3rd. ed.). Oldenbourg.

KLINENBERG, E. (2005). Convergence: News production in a digital age. Convergence. 597 (1).p. 48-64. https://doi.org/10.1177/0002716204270346

KÜNG, L. (2001). The Internet's impact on incumbent media firms: a management perspective. M\&K Medien und Kommunikationswissenschaft. 49 (2). p. 218-226. https://doi.org/10.5771/1615-634x-2001-2-218

LEE, J. K. (2007). The Effect of the Internet on Homogeneity of the Media Agenda: A Test of the Fragmentation Thesis. Journalism \& Mass Communication Quarterly. 84 (4). p. 745-760. https://doi.org/10.1177/107769900708400406

LI, Y. (2017). Contest over authority: Navigating native advertising's impact on journalism autonomy. Journalism Studies. 20 (4). p. 523-541. https://doi.org/10.1 080/1461670X.2017.1397531

MANCINI, P. (2013). Media Fragmentation, Party System, and Democracy. The International Journal of Press/Politics. 18 (1). p. 43-60. https://doi. org $/ 10.1177 / 1940161212458200$

MARR, M. (2003). Soziale Differenzen im Zugang und in der Nutzung des Internet. Aktuelle Befunde aus der Schweiz [Social differences in access and use of the Internet. Current findings from Switzerland]. Medienheft Dossier 19: 19-27.

MARR, M. (2006). Das Internet als politisches Informationsmedium. Eine aktuelle Bestandsaufnahme [The internet as a political information media. A current analysis]. In: Imhof, K. et al. (eds.). Demokratie in der Mediengesellschaft [Democracy in media society]. Wiesbaden: Springer.

NAPOLI, P. M. (2003). Audience economics: Media institutions and the audience marketplace. New York: Columbia University Press.

Napoli, P. M. (2019). Re-evaluation the Long Tail. Implications for Audiovisual Diversity on the Internet. In: Albornoz, L. \& Trinidad Garcia Leiva, M. (eds.). AudioVisual Industries and Diversity. Economics and Policies in the Digital Era. Routledge.

NORRIS, P. (2001). Digital divide: Civic engagement, information poverty, and the Internet worldwide. Communication, society and politics. Cambridge: Cambridge University Press. https://doi.org/10.1017/CBO9781139164887 
OWEN, A. L., \& WEI, A. (2019). Inequality and Bias in the Demand for and Supply of News. Social Science Quarterly. 101 (1).p. 1-16. https://doi.org/10.1111/ ssqu. 12734

PEISER, W., \& JANDURA, O. (2015). Political Media Use. In: Donsbach, W. (ed.) The International Encyclopedia of Communication. Malden: Blackwell.

PIRA INTERNATIONAL (2003). The EU publishing industry: an assessment of competiveness. Luxembourg: European Communities.

RAGNEDDA, M., \& MUTSVAIRO, B. (EDS.) (2018). Communication, globalization, and cultural identity: 2018: 2. Digital inclusion: An international comparative analysis. Lanham: Lexington Books.

RAGNEDDA, M., RUIU, M. L., \& ADDEO, F. (2020). Measuring Digital Capital: An empirical investigation. New Media \& Society. 22 (5). p. 793-816. https://doi. org/10.1177/1461444819869604

ROBINSON, L., COTTEN, S. R., ONO, H., QUAN-HAASE, A., MESCH, G., CHEN, W., SCHULZ, J., HALE, T.M. \& STERN, M. J. (2015). Digital inequalities and why they matter. Information, Communication \& Society. 18 (5). p. 569-582. https://doi.org/10.1080/1369118X.2015.1012532

RONCALLO-DOW, S., \& ARANGO-FORERO, G. A. (2017). Introducing three dimensions of audience fragmentation. Signo y Pensamiento. 36 (70). p. 74-90. https://doi.org/10.11144/javeriana.syp36-70.idaf

SJØVAAG, H., \& KVALHEIM, N. (2019). Eventless news: Blindspots in journalism and the "long tail" of news content. Journal of Applied Journalism \& Media Studies. 8 (3). p. 291-310. https://doi.org/10.1386/ajms_00003_1

THOMAS, G. \& WYATT, S. (2000). Access is not the only problem: using and controlling the Internet. In: Wyatt, S. et al. (eds.) (2000). Technology and in/ equality: Questioning the information society. London: Routledge.

TICHENOR, P. J., DONOHUE, G. A., \& OLIEN, C. N. (1970). Mass Media Flow and Differential Growth in Knowledge. The Public Opinion Quarterly. 34. p. 159-170. Retrieved from http://www.jstor.org/stable/2747414

VAN DEURSEN, A. J., VAN DIJK, J. A., \& HELSPER, E. J. (2014). Who Benefits Most from Being Online? An empirical investigation of outcomes of online engagement. Paper presented at Annual Conference of the International Communication Association (ICA), Seattle, 22-26 May.

VAN DIJK, J. (2004). Digital media. In: Downing, J. D. H. et al. (eds). The SAGE Handbook of Media Studies. Thousand Oaks, London, New Dehli: SAGE Publications.

VAN DIJK, J. (2005). The deepening divide: Inequality in the information society. Thousand Oaks, CA, US: SAGE Publications. 
VAN DIJK, J. (2020). The digital divide: Cambridge, Medford: Policy Press.

WASKO, J. (2004). The Political Economy of Communications. In: Downing, J. D. H. et al. (eds). The SAGE Handbook of Media Studies. Thousand Oaks, London, New Dehli: Sage Publications.

WEI, L., \& HINDMAN, D. B. (2011). Does the Digital Divide Matter More? Comparing the Effects of New Media and Old Media Use on the Education-Based Knowledge Gap. Mass Communication and Society. 14 (2), p. 216-235. https://doi. org/10.1080/15205431003642707

WESSELS, B. (2013). The reproduction and reconfiguration of inequality: Differentiation and class, status and power in the dynamics of digital divides. In: Ragnedda, M. \& Muschert, G. W. (eds.). The Digital Divide The internet and social inequality in international perspective. London: Routledge.

WHITNEY, D. C., SUMPTER, R. S., MCQUAIL, D. (2004). News Media Production: Individuals, Organizations and Instructions. In: Downing, J. D. H. et al. (eds). The SAGE Handbook of Media Studies. Thousand Oaks, London, New Dehli: SAGE Publications.

WIRTZ, B. (2018). Electronic Business. Wiesbaden: Springer.

ZILLIEN, N., \& MARR, M. (2013). The digital divide in Europe. In: Ragnedda, M. \& Muschert, G. W. (eds.). The Digital Divide The internet and social inequality in international perspective. London: Routledge.

ZILLIEN, N., \& HARGITTAI, E. (2009). Digital Distinction: Status-Specific Types of Internet Usage. Social Science Quarterly. 90 (2). p. 274-291. https://doi. org/10.1111/j.1540-6237.2009.00617.x.

ZILLIEN, N. (2006). Digitale Ungleichheit. Neue Technologien und alte Ungleichheiten in der Informations- und Wissensgesellschaft. [Digital inequality. New technologies and old inequalities in the information- and knowledge society] (2nd ed.). Wiesbaden: Springer. 